\title{
Perceptions of voluntary consent among jail diverted veterans with co-
} occurring disorders

Max L. Trojano, B.A. ${ }^{1}$ Paul P. Christopher, M.D. ${ }^{2}$ | Debra A. Pinals, M.D. ${ }^{1,3,4,5}$ | Autumn Harnish, B.A. ${ }^{1,6}$ | David Smelson, Psy.D. ${ }^{1,6}$

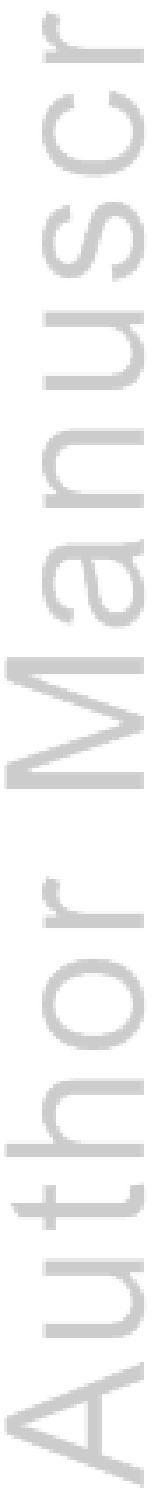

This is the author manuscript accepted for publication and has undergone full peer review but has not been through the copyediting, typesetting, pagination and proofreading process, which may lead to differences between this version and the Version of Record. Please cite this article as doi: $10.1002 / \mathrm{bsl} .2299$

This article is protected by copyright. All rights reserved. 
${ }^{1}$ Department of Psychiatry, University of Massachusetts Medical School, Worcester, MA, USA

${ }^{2}$ Department of Psychiatry and Human Behavior, Brown University, USA

${ }^{3}$ Massachusetts Department of Mental Health, MA, USA

${ }^{4}$ Michigan Department of Health and Human Services, MI, USA

${ }^{5}$ Department of Psychiatry, University of Michigan, MI, USA

${ }^{6}$ Edith Nourse Rogers Memorial Veterans Hospital, USA

\section{Correspondence}

Max L. Trojano, B.A., Department of Psychiatry, University of Massachusetts Medical School, 365 Plantation Street, Suite 100, Worcester, MA 01605, USA

Email: max.trojano@umassmed.edu

\section{Funding information}

Substance Abuse and Mental Health Services Administration, US Department of Health and Human Services, Grant/Award

Number: SM-58804.

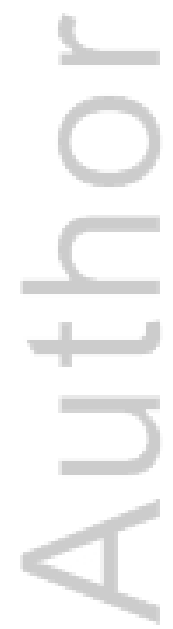

This article is protected by copyright. All rights reserved. 
This study assessed perceptions of voluntary consent among 69 veterans who enrolled in a "jail diversion" program for co-occurring disorders. Perceptions were measured using modified items from the MacArthur Perceived Coercion and Negative Pressure Scales. A majority reported that they "chose to" $(88.4 \%)$ or "felt free to" $(85.5 \%)$ enroll. Most reported having "control over" (69.6\%) and "more influence than anyone else" regarding (60.9\%) their participation. About half reported that enrollment was "their idea" (49.3\%). Fewer reported perceptions of negative pressure, including the feeling that someone "talked them into" enrolling (24.6\%), "threatened them with the maximum criminal punishment" (13.0\%), "offered or promised them something" $(5.8 \%)$, or "forced" them to enroll (5.8\%). Nobody felt "tricked, lied to, or fooled into" participating. Total negative pressure scores were higher in those with combat experience, $U=$ $406.50, p=.016$. Although potentially inappropriate pressures were reported, these data suggest that the majority perceived enrollment as voluntary.

This article is protected by copyright. All rights reserved. 


\section{1 | INTRODUCTION}

Individuals with co-occurring mental health and substance use disorders (CODs) are overrepresented within the criminal justice population (Abram \& Teplin, 1991; Steadman, Osher, Robbins, Case, \& Samuels, 2009). Of particular concern is the number of incarcerated veterans, who in 2012 comprised $8 \%$ of the entire US inmate population, and had generally higher incidences of mental health disorders (48\%-55\%) compared with non-veteran detainees (36\%43\%), particularly in regard to PTSD (Bronson, Carson, Noonan, \& Berzofsky, 2015). Incarcerated veterans also have high rates (60\%) of co-occurring disorders (Finlay et al., 2014), which is not surprising given the research suggesting links between military deployment and mental health issues, including PTSD, depression, and substance misuse (Hoge, Auchterlonie, \& Milliken, 2006; Hoge et al., 2004; Milliken, Auchterlonie, \& Hoge, 2007; Seal et al., 2009). “Jail diversion programs," broadly speaking, offer individuals with mental health and/or substance misuse issues an alternative to incarceration and linkage to community health services, while attempting to reduce criminal recidivism and jail days (Steadman \& Naples, 2005). Many of these programs are linked to criminal case processes, often with some form of correctional supervision (e.g., probation or parole), that involve conditions for adherence and monitoring for non-compliance.

Appropriately, specialized jail diversion programs have been developed for military veterans involved with the criminal justice system (Slattery, Dugger, Lamb, \& Williams, 2013). These programs aim to address the unique issues that veterans face upon returning from service, 
including PTSD, depression, and suicidal ideation, the incidences of which may be increasing due to various changing physical, political, and cultural forces (Hartsfield, 2012; Nidiffer \& Leach, 2010). Jail diversion for veterans is executed through varying models, including participation in specialized veteran treatment courts (VTCs), which number over 250 nationally, or through dockets of drug, mental health, or traditional criminal courts, in which linkage, support, and referral services are provided as a condition of probation (Department of Veterans Affairs, 2016; Smelson et al., 2015). Combined, these efforts highlight the beginning of a paradigm shift towards rehabilitative and, to some extent, restorative jurisprudence for criminally involved service members with underlying mental health and substance use issues (Baldwin \& Rukus, 2015; Seamone et al., 2014).

Jail diversion programs normally require a voluntary enrollment decision, in which the individual can elect for diversion, or instead face standard criminal justice consequences. The stipulations for diversion may include mandatory attendance at court sessions, which are monitored by probation. Because diversion programs begin and often operate within the framework of the criminal justice system, the potential exists for participants to perceive a number of pressures that could potentially undermine their non-compulsory enrollment decision (O'Hear, 2009). Therefore, understanding the perspectives of potential participants during the intake process is an important topic of investigation given that perceptions of coercion have been shown to negatively affect client-provider relationships, engagement in care, recovery, stigma, quality of life, and self-esteem in both civil commitment and voluntary outpatient contexts (Link, 
Castille, \& Stuber, 2008; Stanhope, Marcus, \& Solomon, 2009). Most studies in criminal settings have focused on participation in mental health courts, and have demonstrated that, although the majority of clients are not explicitly aware of the voluntary nature of their participation, the levels of perceived coercion are consistently low (O’Keefe, 2006; Poythress, Petrila, McGaha, \& Boothroyd, 2002; Redlich, Hoover, Summers, \& Steadman, 2010).

Despite the dramatic increase in veteran jail diversion programs (Slattery et al., 2013), little attention has been paid to whether veterans view their enrollment in these programs as voluntary. The need for research in this area is compounded by the fact that veterans present with unique issues, including acculturation to following orders (Olenick, Flowers, \& Diaz, 2015), which could presumably impact their sense of voluntariness in civilian life.

Therefore, the present study focused on perceptions of voluntary enrollment among a sample of veterans entering a jail diversion program attached to probation in non-specialty District Courts, called Maintaining Independence and Sobriety through Systems Integration, Outreach, and Networking_-Diversion and Recovery for Traumatized Veterans (MISSIONDIRECT VET). This service was linked to probation as an alternative to incarceration, but was not part of a specialty court session or docket. To our knowledge, this is the first description of perceptions of voluntary consent obtained from veterans diagnosed with a COD, who were identified during non-specialty court proceedings as candidates for a unique jail diversion program that aimed to address their addiction and mental health needs in the community as an alternative to incarceration. 


\section{2 | METHODS}

\section{1 | Study design}

Data for the present study were drawn from baseline assessments conducted with 69 consecutive participants in a Substance Abuse and Mental Health Services Administration (SAMHSA) funded jail diversion program. Funding was awarded through the Massachusetts Department of Mental Health, in partnership with the Massachusetts Trial Court, which is the overarching administrative entity of Massachusetts court services, as well as the University of Massachusetts Medical School (UMMS) and the University of Massachusetts Boston (UMB). The evaluation of this program was approved by multiple institutional review boards, including the Veterans Administration, UMMS, and UMB.

Inclusion criteria for the program were: (i) agreement to provide written informed consent; (ii) a history of military service; (iii) a recent arrest for which they were deemed eligible by the prosecution to be redirected to the community in lieu of jail; (iv) fulfillment of the DSMIV criteria for trauma-related disorders or other Axis I psychiatric disorders, in conjunction with substance abuse or dependence as defined by the Addiction Severity Index Lite; and (v) being at least 18 years of age at the time of enrollment.

Individuals were ineligible if they: (i) had a medical condition that would make participation, in the opinion of the clinical study director, medically hazardous; (ii) had a severe psychiatric condition in need of urgent treatment or imminent suicide risk; (iii) required immediate medical attention due to dependence on alcohol, benzodiazepines, other depressants, 
or complications of other drug use; (iv) had a moderate to severe history of intellectual disability;

(v) were unable to remain in the geographic service area for the duration of active phase treatment; (vi) were deemed incompetent to stand trial by the presiding judge; or (vii) were deemed by study evaluators as incapable of consenting to the research component of the project.

All participants were recruited from one of four Massachusetts District Courts, which handle misdemeanor, violent, and non-violent felony charges. All participants who met the inclusion criteria provided written informed consent to both the service and the evaluation components of the study. In cases of non-victimless crimes, consent was not required or solicited from the victims. Veterans who declined to participate in the jail diversion program were referred back to the court for standard criminal case processing.

\section{2 | Measures}

To date, there are no validated instruments that specifically measure perceptions regarding the voluntariness of participating in a jail diversion program. Much of the published work on assessing voluntary consent to clinical care, including care that arises within the context of criminal justice involvement (e.g., mental health courts), has relied on questions adapted from the Admission Experience Survey developed in the MacArthur Coercion Study (Gardner et al., 1993), which pertained to issues of voluntary psychiatric treatment and involuntary civil commitment. Consequently, for the present work, we used modified items from two of the MacArthur measures: the Perceived Coercion Scale (PCS) and the Perceived Negative Pressure Scale (NPS) (Gardner et al., 1993; Lidz et al., 1995). 
The PCS is a tool that is intended to measure perceptions of coercion by asking participants whether they agree with five statements about how they view their decision to enroll (Gardner et al., 1993). The NPS, on the other hand, was designed to measure perceived negative pressures (e.g., threats, inducements, and force) from individuals that have the potential to influence decision-making in clinical contexts (e.g., treatment providers) (Lidz et al., 1998). For the present study, other potential sources of external pressure were assessed, including the participant's lawyer, probation officer, judge, family member(s), partner or spouse, and peer(s). Both the PCS and NPS have been shown to have high internal reliability (Gardner et al., 1993; Hiday, Swartz, Swanson, \& Wagner, 1997).

Information regarding demographics (gender, age, race/ethnicity), education level, employment, military service, living situation, and substance use in the past 30 days (prior to incarceration) were also collected. Additional measures included the total and subscale scores for the Behavior and Symptom Identification Scale-24 (BASIS-24), a validated and reliable selfreport instrument used to assess mental health (Eisen, Normand, Belanger, Spiro, \& Esch, 2004). The BASIS-24 contains six subscales including depression and functioning, relationships, emotional lability, psychosis, substance abuse, and self-harm. Total BASIS-24 scores and subscale scores range from 0 to 4 , with 4 being the maximum symptom severity.

\section{3 | Statistical analysis}

Descriptive statistics were used to summarize baseline characteristics for study participants and for responses to each of the items in the PCS and NPS. Additionally, Mann-Whitney $U$ tests and 
Kruskal-Wallis tests were used to assess independence between PCS/NPS total scores and participant characteristics, including the following: (i) age ( $\leq 35,>35$ years old); (ii) education (high school or less, above high school); (iii) race (Caucasian alone, non-Caucasian); (iv) employment (unemployed, employed); (v) military branch of service (Army alone, other branches); (vi) combat history (combat, non-combat); (vii) homelessness in the past 30 days (yes, no); (viii) substance abuse in the past 30 days (yes, no); (ix) total BASIS-24 scores (quartiles); and (x) five of the BASIS-24 subscales, including depression and functioning (quartiles), relationships (quartiles), emotional lability (quartiles), psychosis (quartiles), and substance abuse (quartiles).

\section{$3 \mid$ RESULTS}

\section{1 | Sample characteristics}

Among the 69 veterans who completed the intake assessment (Table 1), the majority were male (94.2\%) and non-Latino white $(81.2 \%)$. The mean age was 37.9 years $(\mathrm{SD}=11.4), 42.0 \%$ had received a high school diploma or equivalent degree, $62.3 \%$ were unemployed, and $8.7 \%$ had experienced homelessness in the previous 30 days. Approximately $46 \%$ had military service in the Army, $56.5 \%$ had been deployed in a combat zone, and $4.3 \%$ reported being active in the military at the time of enrollment. $56.5 \%$ had used at least one illicit substance within the previous 30 days, and the average total BASIS-24 score was $1.4(\mathrm{SD}=0.6)$.

$<\mathrm{TAB} 1>$ 


\section{2 $\mid$ Perceived coercion}

Table 2 presents affirmative responses to the individual PCS items. Regarding their decision to enroll in the jail diversion program, a majority of participants reported that they "felt free" (85.5\%), "chose to" (88.4\%), had "a lot of control over" (69.6\%), and had "more influence than anyone else" (60.9\%). Slightly less than half agreed that jail diversion was their own "idea" (49.3\%). Participants who perceived having less "control over" the decision to enter jail diversion treatment were more likely to be employed, $\chi^{2}(1, n=69)=6.87, p=.009$.

$<\mathrm{TAB} 2>$

\section{3 | Perceived negative pressure}

Affirmative responses to the NPS items are shown in Table 3. No one perceived having been "tricked, lied to, or fooled into" entering jail diversion. A small minority of participants endorsed having the perception that someone "talked them into" (24.6\%), "threatened them with the maximum possible criminal punishment," intended to mean that they were informed that the alternative would be the maximum allowable sentence by law (13.0\%), "offered or promised them something" (5.8\%), or "forced them to" (5.8\%) participate in the program. Those who answered affirmatively to these items tended to report the intensity of the perceived pressure as more than "a little." Additionally, the majority indicated that the pressure came from someone within the criminal justice system (e.g., judge, lawyer, or probation officer), as opposed to clinical or extralegal sources, such as family members or peers. All four of the participants who perceived being "forced into" jail diversion were employed, $\chi^{2}(1, n=69)=9.71, p=.007$. 
$\langle\mathrm{TAB} 3>$

\section{4 | Total PCS and NPS scores}

As shown in Figure 1, the mean PCS score was $1.46(\mathrm{SD}=1.37)$ and the mean NPS score was $0.49(\mathrm{SD}=0.72)$. Total NPS scores were significantly higher for those with reported combat experience, $U=406.5, p=.016$. Total PCS scores tended to be higher among those who were employed, although this association was not statistically significant, $U=374.5, p=.081$.

Otherwise, total PCS and NPS scores were not significantly associated with any participant demographic or clinical characteristic.

$<$ FIG 1 >

\section{4 | DISCUSSION}

To our knowledge, this is the first study to examine perceptions of voluntary consent to enroll in a jail diversion program intended to address co-occurring disorders in veterans. These findings suggest that a majority of participants perceived their decision to enter into jail diversion as voluntary. Nevertheless, a small minority endorsed items suggesting that their choice to enroll may have been influenced by one or more perceived pressures that potentially constrained the autonomy of their decision.

In all but one of the PCS items, the majority of participants responded in a manner suggesting that their decisions were voluntary. Specifically, over $85 \%$ indicated that they "felt free" and "chose to" enroll, while $60 \%$ and $70 \%$ reported having "a lot of control" and "more 
influence than anyone else" about entering the program respectively. In contrast, less than 50\% agreed that jail diversion was their "idea."

Inferences based on these results should be made cautiously, as some of the PCS items can be interpreted in ways that do not suggest critical influence on voluntary decision making (Appelbaum, Lidz, \& Klitzman, 2009). For example, the item that asks if jail diversion was the individual's "idea," is particularly indistinct. Indeed, many participants may have had no knowledge of the opportunity to participate in a jail diversion program; it may have been brought to their attention by their lawyer, a judge, or a peer. In other words, the mere fact that a participant was given the "idea" of entering jail diversion by someone else should not be concerning.

Similarly, most participants reported an absence of negative pressure to participate in jail diversion treatment. No one felt "tricked, lied to, or fooled into" enrolling. Nevertheless, a small number of veterans indicated their belief that someone either "talked them into," "threatened them with the maximum possible criminal punishment," "offered or promised something," or "forced them to participate." Moreover, when these pressures were perceived, they tended to be felt more than just to "a little" extent. However, as with the PCS, some items on the NPS are somewhat imprecise. The item regarding "maximum possible criminal punishment," for instance, could be taken to mean the maximum statutory sentence, or rather a relatively harsh punishment in the opinion of the individual. 
While still potentially concerning, the implications of these findings primarily suggest a need for greater understanding of the circumstances surrounding recruitment. For example, like many difficult decisions, having to choose whether to enroll in jail diversion treatment in lieu of incarceration as a consequence to criminal activity is subject to intrinsic psychological pressure (Ryan \& Whelan, 2012). Thus, a veteran facing jail time may feel "forced" to enroll when the only other option is incarceration. Additionally, veterans who are accustomed to following orders may perceive communication in civilian contexts to be more forceful than intended (Olenick et al., 2015). For instance, veterans may perceive pressure after informal consultation with a legal authority figure, such as a probation officer or a lawyer who understands the consequences of non-participation and therefore supports jail diversion as a positive disposition for the criminal case. Indeed, these individuals may also be the first to raise jail diversion as a potential disposition with the veteran. In this vein, it makes sense that criminal justice personnel were most often identified as sources of perceived negative pressure, as they acted as the first filter for enrollment before the involvement of clinicians. However, due to the fact that circumstantial details underlying perceived negative pressure are not captured by the NPS (Klag, Creed, \& O'Callaghan, 2006), it is impossible to conclude whether these data are problematic. As such, it is important to continue to understand the dialogue between veterans and persons engaging them in discussion during the enrollment process.

One potentially important detail that may underlie these interactions is combat experience. We found that total NPS scores were significantly higher in those with combat 
involvement, compared with veterans with no combat experience. This relationship could be due to a disparate ability to follow orders, or the perception of risk in not following orders. For example, veterans facing physical combat may be more likely to adhere to commands than noncombat veterans, as disobedience on the battlefield could result in injury, or even death.

Therefore, in terms of this study, combat veterans may have been predisposed to perceive an obligation to enroll due to their acculturation to compliance. Not mutually exclusive, the presence of PTSD, which has been shown to increase with combat experience (Hoge et al., 2004), may also explain the incongruent NPS scores. Although the relationship between combatrelated PTSD and perceptions of voluntary participation have not been studied directly in any context, there is some evidence to suggest that the sequelae associated with PTSD may affect decision making in stressful situations (Starcke \& Brand, 2012). Decision making related to enrollment in a jail diversion program may or may not be perceived as a stressor, but it may be worth further investigation.

The data from this study also suggest that participants who report employment at the time of their arrest may be more likely to perceive the time and clinical commitments associated with jail diversion as potentially disruptive to their occupational responsibilities. If this is indeed the case, a perception of having less control and/or being forced to enter the program may partly reflect a fear that participation in jail diversion might implicate one's job and lead to greater pressure in the decision making process. 
With the limitations of the scales and small sample size aside, future research involving this population should investigate the consequences of these perceptions, as the research to date has been limited and inconclusive. Notably, however, perceived coercion was found to be a poor predictor of service engagement in a study of civilian jail diversion programs (Cusack,

Steadman, \& Herring, 2010), but not in mental health courts, where perceptions of coercion and negative pressure were found to be negatively associated with perceptions of recovery and recidivism respectively (Pratt, Yanos, Kopelovich, Koerner, \& Alexander, 2013). In the interim, jail diversion programs should attempt to mitigate these perceptions during enrollment. As suggested by studies of mental health courts, one possible way to do this is to ensure that all participants are provided with detailed information regarding court procedures and requirements, followed by subsequent checks for comprehension (Redlich et al., 2010).

\section{5 | CONCLUSION}

Overall, we believe that these findings show positive sentiments and minimal coercion in the veteran population under study for this program. That said, continued attention to the mechanics of client engagement as well as perceptions of voluntariness versus negative pressure, particularly within the framework of jail diversion programs, will be crucial for identifying and understanding the variables underlying participant success over time.

\section{REFERENCES}


Abram, K. M, \& Teplin, A. (1991). Co-occurring disorders among mentally ill jail detainees: Implications for public policy. American Psychologist, 46(10), 1036-1045. doi:10.1037/0003-66X.46.10.1036

Appelbaum, P. S., Lidz, C. W., \& Klitzman, R. (2009). Voluntariness of consent to research: A conceptual model. Hastings Center Report, 31(6), 30-39. doi:10.1353/hcr.0.0103

Baldwin, J. M., \& Rukus, J. (2015). Healing the wounds: An examination of veterans treatment courts in the context of restorative justice. Criminal Justice Policy Review, 26(2), 183207. doi:10.1177/0887403413530002

Bronson, J., Carson, A., Noonan, M., \& Berzofsky, M. (2015). Veterans in prison and jail, 2011-2012. Retrieved January 12, 2017, from Bureau of Justice Statistics Website: https://www.bjs.gov/index.cfm?ty=pbdetail\&iid=5479

Cusack, K. J., Steadman, H. J., \& Herring, A. H. (2010). Perceived coercion among jail diversion participants in a multisite study. Psychiatric Services, 61(9), 911-916. doi:10.1176/appi.ps.61.9.911

Department of Veterans Affairs. (2016). Veterans court inventory 2014 update: Characteristics of and VA involvement in veterans treatment courts, dockets, and tracks from the veterans justice outreach specialist perspective. Retrieved January 12, 2017, from Department of Veterans Affairs Website: http://www.va.gov/homeless/vjo.asp

This article is protected by copyright. All rights reserved. 
Eisen, S. V., Normand, S. L., Belanger, A. J., Spiro, A., \& Esch, D. (2004). The revised Behavior and Symptom Identification Scale (BASIS-R): Reliability and validity. Medical Care, 42(12), 1230-1241. doi:10.1097/00005650-200412000-00010

Finlay, A. K., Smelson, D. A., Sawh, L., McGuire, J., Rosenthal, J., Blue-Howells, J., ... Harris, A. H. S. (2014). US Department of Veterans Affairs Veterans Justice Outreach Program: Connecting justice-involved veterans with mental health and substance use disorder treatment. Criminal Justice Policy Review, 27(2), 203-222.

doi:10.1177/0887403414562601

Gardner, W., Hoge, S. K., Bennett, N., Roth, L. H., Lidz, C. W., Monahan, J., \& Mulvey, E. P. (1993). Two scales for measuring patient's perceptions for coercion during mental hospital admission. Behavioral Sciences and the Law, 11(3), 307-321.

doi:10.1002/bsl.2370110308

Hartsfield, C. H. (2012). Deportation of veterans: The silent battle for naturalization. Rutgers Law Review, 64(3), 835-862.

Hiday, V. A., Swartz, M. S., Swanson, J., \& Wagner, H. R. (1997). Patient perceptions of coercion in mental hospital admission. International Journal of Law and Psychiatry, 20(2), 227-241. doi:10.1016/S0160-2527(97)00004-6

Hoge, C. W., Auchterlonie, J. L., \& Milliken, C. S. (2006). Mental health problems, use of mental health services, and attrition from military service after returning from

This article is protected by copyright. All rights reserved. 
deployment to Iraq or Afghanistan. Journal of the American Medical Association, 295(9), 1023-1032. doi:10.1001/jama.295.9.1023

Hoge, C. W., Castro, C. A., Messer, S., McGurk, D., Cotting, D. I., \& Koffman, R. L. (2004).

Combat duty in Iraq and Afghanistan, mental health problems, and barriers to care. New England Journal of Medicine, 351(1), 13-22. doi:1056/NEJMoa040603

Klag, S., Creed, P., \& O’Callaghan, F. (2006). Development and initial validation of an instrument to measure perceived coercion to enter treatment for substance abuse. Psychology of Addictive Behaviors, 20(4), 463-470. doi:10.1037/0893-164X.20.4.463

Lidz, C. W., Hoge, S. K., Gardner, W., Bennett, N. S., Monahan, J., Mulvey, E. P., \& Roth, L. H. (1995). Perceived coercion in mental hospital admission. Pressures and process. Archives of General Psychiatry, 52(12), 1034-1039. doi:10.1001/archpsyc.1995.03950240052010

Lidz, C. W., Mulvey, E. P., Hoge, S. K., Kirsch, B. L., Monahan, J., Eisenberg, M., .. Roth, L. H. (1998). Factual sources of psychiatric patients' perceptions of coercion in the hospital admission process. American Journal of Psychiatry, 155(9), 1254-1260. doi:10.1176/aip.155.9.1254

Link, B., Castille, D. M., \& Stuber, J. (2008). Stigma and coercion in the context of outpatient treatment for people with mental illnesses. Social Science and Medicine, 67(3), 409-419. doi:10.1016/j.socscimed.2008.03.015

Milliken, C. S., Auchterlonie, J. L., \& Hoge, C. W. (2007). Longitudinal assessment of mental health problems among active and reserve component soldiers returning from the Iraq 
war. Journal of the American Medical Association, 298(18), 2141-2148.

doi:10.1001/jama.298.18.2141

Nidiffer, F. D., \& Leach, S. (2010). To hell and back: Evolution of combat-related post traumatic stress disorder. Developments in Mental Health Law, 29(1), 1-22.

O’Hear, M. (2009). Rethinking drug courts: Restorative justice as a response to racial injustice. Stanford Law and Policy Review, 20, 463-499.

O'Keefe, K. (2006). The Brooklyn Mental Health Court evaluation: Planning, implementation, courtroom dynamics, and participant outcomes. Retrieved January 12, 2017, from Center for Court Innovation Website: http://www.courtinnovation.org/research/brooklyn-mentalhealth-court-evaluation-planning-implementation-courtroom-dynamics-and-part

Olenick, M., Flowers, M., \& Diaz, V. J. (2015). US veterans and their unique issues: Enhancing health care professional awareness. Advances in Medical Education and Practice, 6, 635639. doi:10.2147/AMEP.S89479

Poythress, N. G., Petrila, J., McGaha, A., \& Boothroyd, R. (2002). Perceived coercion and procedural justice in the Broward mental health court. International Journal of Law and Psychiatry, 25(5), 517-533. doi:10.1016/S0160-2527(01)00110-8

Pratt, C., Yanos, P. T., Kopelovich, S. L., Koerner, J., \& Alexander, M. J. (2013). Predictors of criminal justice outcomes among mental health participants: The role of perceived coercion and subjective mental health recovery. International Journal of Forensic Mental Health, 12(2), 116-125. doi:10.1080/14999013.2013.791351 
Redlich, A. D., Hoover, S., Summers, A., \& Steadman, H. J. (2010). Enrollment in mental health courts: Voluntariness, knowingness, and adjudicative competence. Law and Human Behavior, 34(2), 91-104. doi:10.1007/s10979-008-9170-8

Ryan, S., \& Whelan, D. (2012). Diversion of offenders with mental disorders: Mental health courts. Web Journal of Current Legal Issues. Retrieved January 12, 2017, from http://webjcli.ncl.ac.uk/2012/issue1/ryan1.html

Seal, K. H., Metzler, T. J., Gima, K. S., Bertenthal, D., Maguen, S., \& Marmar, C. R. (2009). Trends and risk factors for mental health diagnoses among Iraq and Afghanistan veterans using Department of Veterans Affairs health care, 2002-2008. American Journal of Public Health, 99(9), 1651-1658. doi:10.2105/AJPH.2008.150284

Seamone, E. R., McGuire, J., Sreenivasan, S., Clark, S., Smee, D., \& Dow, D. (2014). Moving upstream: Why rehabilitative justice in military discharge proceedings serves a public health interest. American Journal of Public Health, 104(10), 1805-1811. doi:10.2105/AJPH.2014.302117

Slattery, M., Dugger, M. T., Lamb, T. A., \& Williams, L. (2013). Catch, treat, and release: Veteran treatment courts address the challenges of returning home. Substance Use and Misuse, 48(10), 922-932. doi:10.3109/10826084.2013.797468

Smelson, D. A., Pinals, D. A., Sawh, L, Fulwiler, C., Singer, S., Guevremont, N., ... Hartwell, S. (2015). An alternative to incarceration: Co-occurring disorders treatment intervention for

This article is protected by copyright. All rights reserved. 
justice-involved veterans. World Medical and Health Policy, 7(4), 329-348.

doi:10.1002/wmh3.168

Stanhope, V., Marcus, S., \& Solomon, P. (2009). The impact of coercion on services from the perspective of mental health care consumers with co-occurring disorders. Psychiatric Services, 60(2), 183-188. doi:10.1176/appi.ps.60.2.183

Starcke, K., \& Brand, M. (2012). Decision making under stress: A selective review.

Neuroscience and Biobehavioral Reviews, 36(4), 1228-1248.

doi:10.1016/j.neubiorev.2012.02.003

Steadman, H. J., \& Naples, M. (2005). Assessing the effectiveness of jail diversion programs for persons with serious mental illness and co-occurring substance use disorders. Behavioral Sciences and the Law, 23(2), 163-170. doi:10.1002/bsil.640

Steadman, H. J., Osher, F. C., Robbins, P. C., Case, B., \& Samuels, S. (2009). Prevalence of serious mental illness among jail inmates. Psychiatric Services, 60(6), 761-765. doi:10.1176/ps.2009.60.6.761

This article is protected by copyright. All rights reserved. 
TABLE 1 Characteristics of jail diversion participants

\begin{tabular}{|c|c|c|}
\hline Characteristic & $N=69$ & $\%$ \\
\hline \multicolumn{3}{|l|}{ Gender } \\
\hline Male & 65 & 94.2 \\
\hline Female & 4 & 5.8 \\
\hline Mean age (SD) & $37.9(11.4)$ & \\
\hline \multicolumn{3}{|l|}{ Race } \\
\hline Caucasian & 56 & 81.2 \\
\hline African American & 8 & 11.6 \\
\hline$=$ Mixed race & 4 & 5.3 \\
\hline Other & 1 & 1.4 \\
\hline \multicolumn{3}{|l|}{ Education } \\
\hline$<12$ years & 1 & 1.4 \\
\hline Voc/tech & 2 & 2.9 \\
\hline High school diploma/GED & 29 & 42.0 \\
\hline Some college & 33 & 47.8 \\
\hline$\geq$ Bachelor's degree & 4 & 5.8 \\
\hline \multicolumn{3}{|l|}{ Employment } \\
\hline Employed & 21 & 30.4 \\
\hline Unemployed & 43 & 62.3 \\
\hline Other & 5 & 7.2 \\
\hline \multicolumn{3}{|l|}{ Homelessness in past 30 days } \\
\hline Yes & 6 & 8.7 \\
\hline No & 54 & 78.3 \\
\hline Don't know or refused & 9 & 13.0 \\
\hline \multicolumn{3}{|l|}{ Military branch } \\
\hline Army & 32 & 46.4 \\
\hline Marine Corps & 22 & 28.9 \\
\hline Air Force & 8 & 11.6 \\
\hline Navy & 4 & 5.8 \\
\hline Multiple & 4 & 5.8 \\
\hline \multicolumn{3}{|l|}{ Military deployment } \\
\hline Combat zone & 39 & 56.5 \\
\hline Non-combat zone & 30 & 43.5 \\
\hline \multicolumn{3}{|l|}{ Military status } \\
\hline Currently active & 3 & 4.3 \\
\hline Separated from service & 66 & 95.7 \\
\hline \multicolumn{3}{|l|}{ Substance use in past 30 days } \\
\hline Yes & 39 & 56.5 \\
\hline No & 20 & 29.0 \\
\hline Don't know or refused & 10 & 14.5 \\
\hline Mean total BASIS-24 score (SD) & $1.4(0.6)$ & \\
\hline
\end{tabular}


TABLE 2 Affirmative responses to PCS items

Item

n $\%$

Did you choose to enter jail diversion treatment?

$61 \quad 88.4$

Did you feel free to do what you wanted about entering jail diversion treatment?

59

85.5

2

Did you have a lot of control over whether you entered jail diversion treatment?

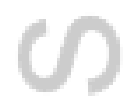

Did you have more influence than anyone else about whether you entered jail diversion treatment?

Was it your idea to receive jail diversion treatment?

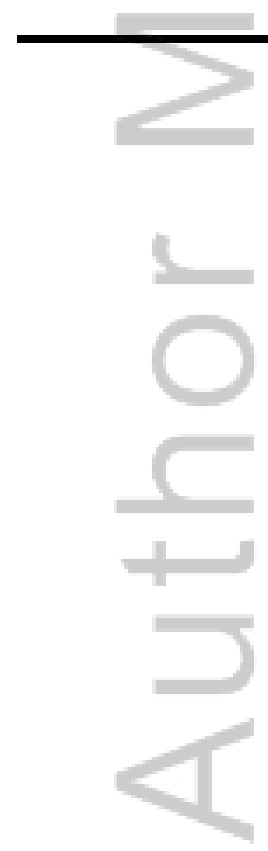

This article is protected by copyright. All rights reserved. 
TABLE 3 Affirmative reponses to NPS items

\begin{tabular}{lccc}
\hline Item & $\boldsymbol{n}$ & $\mathbf{\%}$ \\
\hline Did anyone try to talk you into entering jail diversion treatment? & 17 & 24.6 \\
& Lawyer & 9 & 52.9 \\
Probation officer & 4 & 23.5 \\
Treatment provider & 2 & 11.8 \\
Judge & 1 & 5.9 \\
Other & 1 & 5.9 \\
Intensity & & \\
Not at all & 1 & 5.9 \\
A little & 2 & 11.8 \\
Some & 6 & 35.3 \\
Very much & 8 & 47.0
\end{tabular}

Did anyone threaten you with the maximum possible criminal punishment to get you to enter jail diversion treatment?

Judge

$9 \quad 13.0$

Treatment provider

$5 \quad 55.6$

Intensity

$4 \quad 44.4$

A little

Some

Very much

$2 \quad 22.2$

$1 \quad 11.1$

$6 \quad 66.7$

Did anyone offer or promise you something to get you to enter jail diversion treatment?

Judge
Lawyer
Peer
Intensity
Some
Very much

Did anyone force you to participate in jail diversion treatment?

Judge
Probation officer
Treatment provide
Intensity
Very much

$4 \quad 5.8$

250.0

$1 \quad 25.0$

125.0

$3 \quad 75.0$

$1 \quad 25.0$

$4 \quad 5.8$

250.0

$1 \quad 25.0$

125.0

$4 \quad 100.0$

This article is protected by copyright. All rights reserved. 
Did anyone trick you, lie to you, or fool you into entering jail diversion

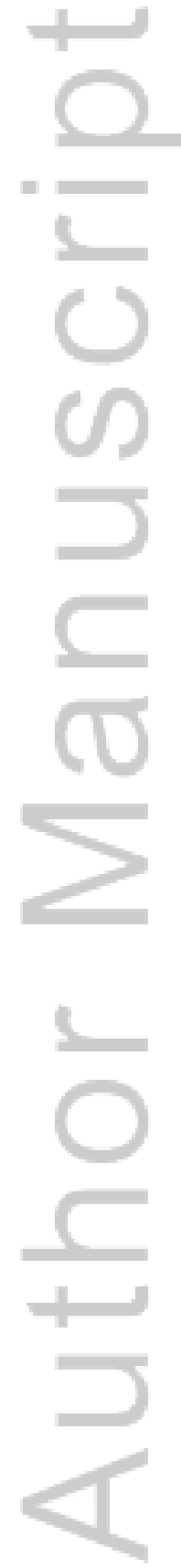

This article is protected by copyright. All rights reserved. 
FIGURE 1 Distribution of total PCS and NPS scores

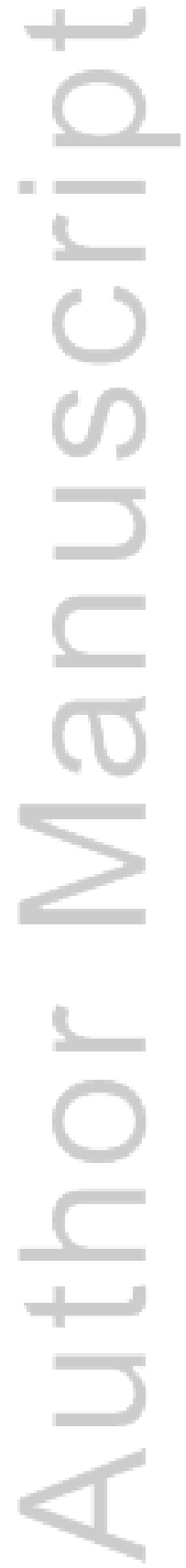

This article is protected by copyright. All rights reserved. 
ARTICLE FRONT SHEET

<ARTTY ARTTY="XX">

(Select from RA, RV, RL, SC, ED, BR, ER, CR, XX)

<CATEG >Special Issue Article</CATEG>

<TOCCATEG>Special Issue Articles</TOCCATEG>

<FIGCT COUNT="0"> <TABCT COUNT="0" > <REFCT COUNT="34">

$<$ CRNG PUBL="YES" $><$ CRLN $>$ Copyright \&copy; 2014 John Wiley \&amp; Sons, Ltd. $</ C R L N>$

$<$ CRNM > John Wiley \&amp; Sons, Ltd.</CRNM > <CRYR YEAR="2017" ></CRYR > </CRNG $>$

\section{First page headline}

cemafs99.doc last updated 25-Sep-1998

Behavioral Sciences and the Law

Behav. Sci. Law 34: 000-000 (2017)

Published online in Wiley Online Library (wileyonlinelibrary.com). DOI: 10.1002/bsl.2299

Article title < Perceptions of voluntary consent among jail diverted veterans with co-occurring disorders $>$

Please see manuscript for details (Please write article title here in SGML sentence-case form)

Run on at end of abstract

Copyright (c) 2017 John Wiley \& Sons, Ltd.

Running headlines

Recto $<$ VOLUNTARY CONSENT AMONG JAIL DIVERTED VETERANS $>$

Verso $<\underline{\text { M.L Trojano et al. }>}$

Running footlines (recto and verso)

Copyright (c) 2017 John Wiley \& Sons, Ltd.

Behav. Sci. Law 34: 000-000 (2017)

Footnote giving corresponding author and address

*Correspondence to:

$<$ CORR > Max L. Trojano, Department of Psychiatry, University of Massachusetts Medical School, 365 Plantation

Street, Suite 100, Worcester, MA 01605, USA $</ C O R R>$

First page footlines

Copyright @ 2016 John Wiley \& Sons, Ltd.

If there are other SGML tags required for this article, such as Special editor <SPEDG> (at ms level) (SPED, FNMS, SNM, AFFS); Conference group <CNG> $(C N D F, C N D L, C N M, C N N, C N P, C N S)$; or Contract/grant info <CG> (CGS, CGN) then please write the details beneath here (and continue overleaf).

\begin{tabular}{|c|c|c|}
\hline \multicolumn{3}{|c|}{ PROOFING INSTRUCTIONS } \\
\hline Author E-mail & max.trojano@umassmed.edu & \\
\hline \multicolumn{3}{|l|}{ Editor } \\
\hline \multicolumn{3}{|l|}{ Editor E-mail } \\
\hline & Yes & Copyright Transfer Agreement (CTA) \\
\hline
\end{tabular}

\begin{tabular}{|l||c||c||c||c||c||}
\hline \hline No. disks & 23 & No. folios & 0 & $\begin{array}{c}\text { No. sheets of } \\
\text { artwork }\end{array}$ & $\begin{array}{c}\text { Manuscript typeset } \\
\text { ONLY }\end{array}$ \\
\hline
\end{tabular}

This article is protected by copyright. All rights reserved. 


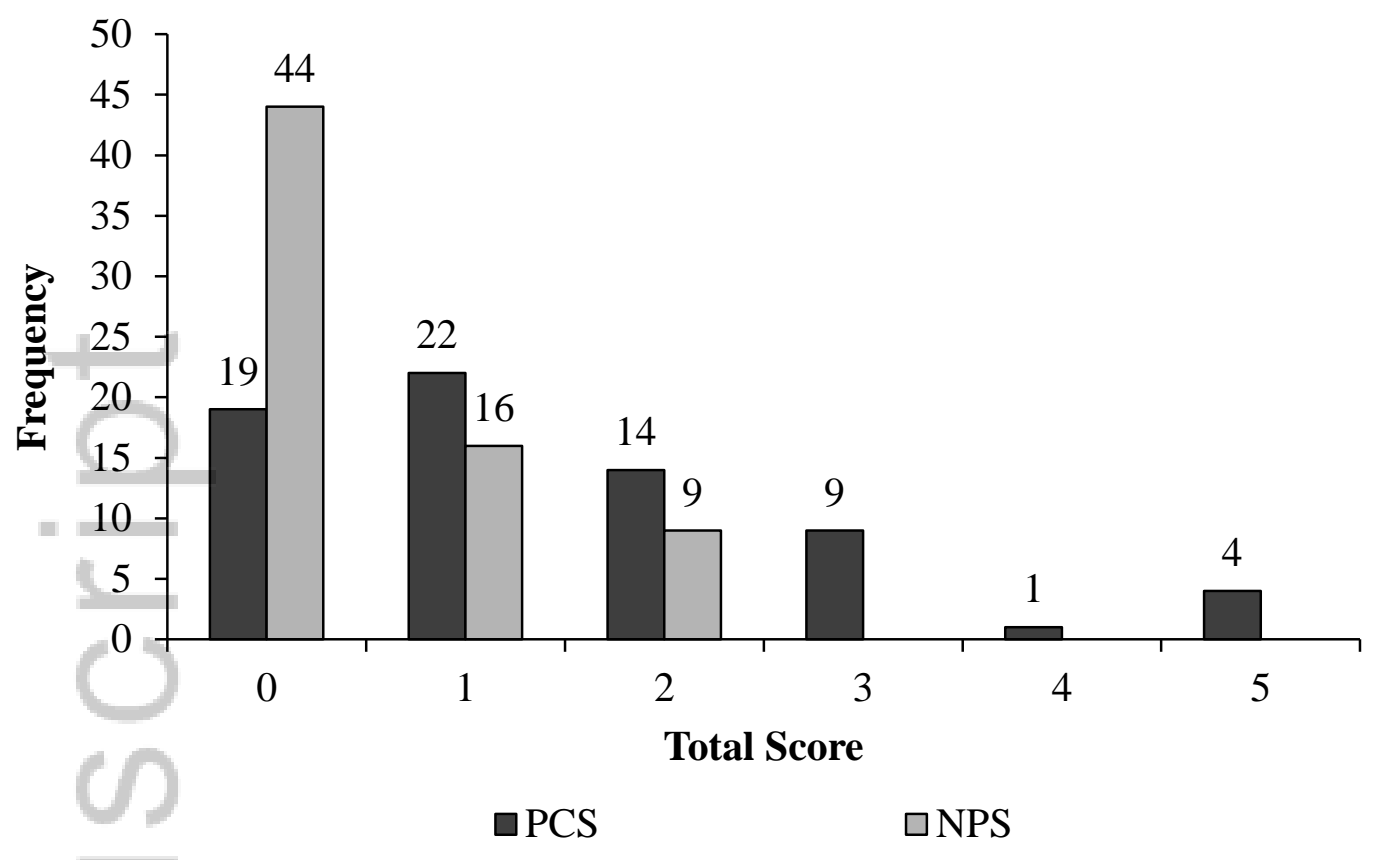

Note: Distributions of total PCS $(\bar{x}=1.46, \mathrm{SD}=1.37)$ and NPS scores $(\bar{x}=0.49, \mathrm{SD}=0.72)$ ranged from 0 to 5. Each "no" response on the PCS and each "yes" response on the NPS was given a score of 1 .

This article is protected by copyright. All rights reserved. 


\section{Author queries}

Please provide city locations for all affiliations.

p 15 line 2 'Whelen' has been changed to 'Whelan' so that this citation matches the Reference List. Please confirm that this is correct.

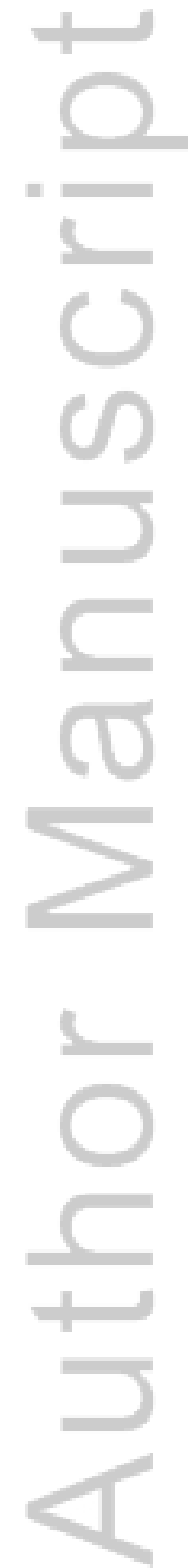

This article is protected by copyright. All rights reserved. 